\title{
Sea Sport Safety Assessment
}

\section{Izhar Mohd Mustaat, Muhammad Irsyad Hasbullah a,*, Mohd Hafizi Said, Megat Khalyd Al-Walyd Megat Mohd Rosdeen, Muhammad Faiz Amir Heberd, Muhammad Amirul Mukmin Bin Roslan}

\author{
Program of Nautical Science and Maritime Transportation, School of Ocean Engineering, \\ Universiti Malaysia Terengganu, Kuala Nerus, Terengganu, MALAYSIA \\ a. irsyadhasbullah@gmail.com \\ *corresponding author
}

Keywords: HAZID, Sea Sport.

Abstract: Sea sport is one of the main attractions in Kuala Terengganu, the capital city of Terengganu, Malaysia. The type of seaport activities such as sailing, windsurfing, parasailing, fly boarding, canoes, are enjoyed by a growing number of Malaysians. As popularity increases, the numbers of accidents are growing rapidly. From the general observation, it showed that the awareness on safety aspects such as using proper equipment, suitable attire and enforcement of regulations are still lacking. All these issues have raised the concern to conduct a risk assessment on each sea sports activities. This research method was started with identifying the type of hazards for each sea sports activities by using HAZID method. Each of the hazards was individually analyzed and evaluated by using risk matrix in order to calculate the risk level. These risks obtained from this research are classified into four major classes which is General risk, Equipment (kit), weather and water. These classes states where the risk is initiated and what result does it contributed. The measurement level of severity of the injuries was sorting by the scale from one and to five and further analysis was made in the form of percentage. Result shows some of the activities may involve in minor and serious injuries. From the overall result, some of the most crucial hazards are drowning, head injury and other common injuries. Therefore, some of the recommendation were made as for prevention such as better supervision, maintaining good facilities and sport equipment and awareness on safety precautions of the sea sport activities.

\section{Introduction}

The popularity of sea sport has arisen with new types of sea sports activities involved. However, it requires a huge amount of knowledge and safety awareness as safety is vital for everyone. It is about building confidence to get involve in sea sports with the knowledge on the risk of sea sports. Thus, at the same time, minimizing these risks in sea sports and safety will be the first priority.

Annually the number of person engaging in sea sports keep rising. Therefore, the probability of mishaps and accidents happening also increases. Consequently, every person engaging in sea sports must have the ability to identify the risks related to these activities and must equip themselves in advance so that any potentially risky and dangerous circumstances could be avoided [2]. The objective of any safety precautions is to mitigate the probability of accidents. Regardless of the precautions that were taken, accidents will still occur. Different activities have different risk and preparation is essential in order to minimize those risk [1]. 
Based on the observation and data from water sports activities held in Pulau Duyong, Terengganu it recorded a number of cases which involve major and minor injuries as well as loss and damage to property. These cases will likely increase, and prevention should be made to reduce any unlikely event. To show how crucial this problem is from the outside of this country, in 2005 ,the Centers for Disease Control and Prevention survey reported that more than 4000 deaths caused by different kinds of water sports activities for that year [2].

Some of the cases that arise will cause some problems towards the area authorities including complaint letter and legal redress. Therefore, it is essential to be acquainted with basic safety awareness involving sea sports activities that will help person engaging in those activities to take appropriate precautions prior to and during the conduct of the activity whether near or in the water. The significance of this study is to raise awareness to the stake holders and for the benefit of sea sports development and future use. Moreover, from this research, a solution can be identified through risk matrix analysis and risk control options.

The objective of this study is to conduct risk assessment of sea sports activities at Pulau Duyong to enhance safety and reputation of Pulau Duyong. In order to perform the risk assessment, the first step will be hazard identification (HAZID), second, evaluation of the risks using the risk matrix to record the significant findings and third, provide control options for each of the hazard. Finally, this paper provides possible recommendation and solution on the identified risks.

\section{Literature Review}

\subsection{Introduction}

The benefits of sea sport and physical activity can last a lifetime, with many youngsters are now experiencing millennium era of technologies. When considered against other activities, physical sea recreational activities can be thought of as being 'high risk' [4]. This means that activities need careful consideration, but safety measures shall not be put aside and enjoyment of sport and physical activity. In this research, to achieve the objectives of the research, we are using the risk assessment steps. This enable us to analyze the hazard of the sea sport.

\subsection{Risk Assessment}

The purpose of a risk assessment is to identify practical and effective measures to control the risks in a particular area. It would most probably involve taking steps to protect someone from injury and illness, and this method would help to assess and decide what are elements that need to be prevented and protected from hazards. It focuses on the probability of accidents and illness occurring and concentrate on real risks that are most likely to happen and that which will cause the most damage [8].

Certain regulatory requirements may require specific control measures for some type of risks. This assessment would enable the identification of certain risks and their control measures in more detail. The control measures may be assessed as part of, or an extension of the overall risk assessment.

There are no specific rules on how a risk assessment should be conducted, but there are a few general principles that should be adhered to. There are steps in risk assessment method that can be followed to ensure that it is conducted correctly. First, the identification of the hazards in order to differentiate between the hazard and risk. Second, evaluate the risks. After 'hazard identification' and 'determining its consequences' its risk control options will be identified to avoid those hazard from taking place. The hazards that was identified can either be removed completely or the risks 
controlled so that the damage or injury is unlikely. Third, record the findings and provide recommendations for implementation of control options for identified hazards [9].

\subsection{Sea Sport}

In the last fifteen years, there has been a dramatic increase on studies about various sailing aspects. The hard work to advance evidence-based data on sailing and sports medicine have face many unique impediments. Historically, sailing medicine has been addressed by healthcare professionals who are sailors, receiving minimal support for their efforts. With the recent interest in research by groups such as Olympic and America's Cup teams, this scenario has seen noteworthy changes [4].

From our research finding, it supported the literature review that is stated. The sailing activities in Terengganu are well developing from time to time. Therefore, the knowledge about this sport must be adapted towards the society since the result prove that safety culture among sailors is still at a low level based on interviews and observation from the risk assessment technique. The literature review and the expert opinions provided suggests that there are injury patterns, fitness and training techniques, physiological and psychological demands that are specific to sailing. These performance components are explicit to boat classes and crew positions and constantly change with the environment of the sport. By addressing these components and developing further studies, knowledge of sailing will improve, and damage or injuries may be prevented.

\subsection{Knowledge or awareness}

Water safety awareness includes a range of strategies and activities designed to keep people safe when engaged in sea sports activities. According to Safe Water Sport article, society should be informed on safety issues and regulations about water sports and water activities. Maximizing safety while involved in water sports involves knowledge of risks and how to avoid or minimize it. In this study, the level of awareness from the water sports society must be measured to know what factors that will affect safety in the water. This awareness is based on water familiarization, checking for water hazards, obeying rules and knowledge of Basic Swimming Skills. Based on Malaysia statistic on drowning, annually, the country recorded 700 cases of drowning, of which 500 involved children, aged between one and 18-years-old [3]. Thus, in this research study aims to reveal does the low level of awareness might cause decreases in the chance of surviving and increases in drowning and death cases

\subsection{Equipment}

This research corresponds to an article on the Essential Safety Equipment for Sports. For example, according to the American Academy of Ophthalmology, more than ninety percent of all sportsrelated eye injuries can be prevented with the use of appropriate protective eyewear. This advice applies to athletes or anyone who participates in any type of sports. There are a variety of clear as well as tinted sunglasses and goggles for nearly every sport that could keep their eyes protected [6].

Generally, all sport requires proper equipment, same as the water sport which contributes to more efficient safety prevention and risk reduction based on HAZID analysis. The right protective safety gear for the particular sport is essential for avoiding serious injuries or reducing the severity of an injury that may occur. However, accidents may occur occasionally during sea sports activities which may cause damage to the equipment. Fortuitously, in most cases, participants can apply selfrescue technique to help themselves. It is only in a very small number of cases that participants have to rely entirely on others for rescue [5]. 


\subsection{Supervision}

Due to some safety cases that arise in Pulau Duyung, some of concerning factors are the supervision. This is subjected to sufficient amount of trained lifeguard or any other supervise body especially during any sailing tournament or while doing the recreational water sports. Supervision in our scope is the act of supervising people in, on or near water because it is very vital for their safety. Some athletes involved in sea sports or other water activities usually do not even bother about supervision and even involving in these activities without having supervision is a norm in their normal training days. Proper supervision around water requires an experienced adult in term of swimming and saving people in danger or a lifeguard to keep other people in their care within sight and reach all the times.

\section{Methodology}

\subsection{Research Design}

This research design was determined by the objectives of this research which is to conduct risk assessment on sea sports activities at Pulau Duyong in order to enhance the safety level in the area. These are the steps that are consist in risk assessment;

- Identify the hazards

- Evaluate the risks using the risk matrix table

- Record the significant findings and provide control options for each of the hazard.
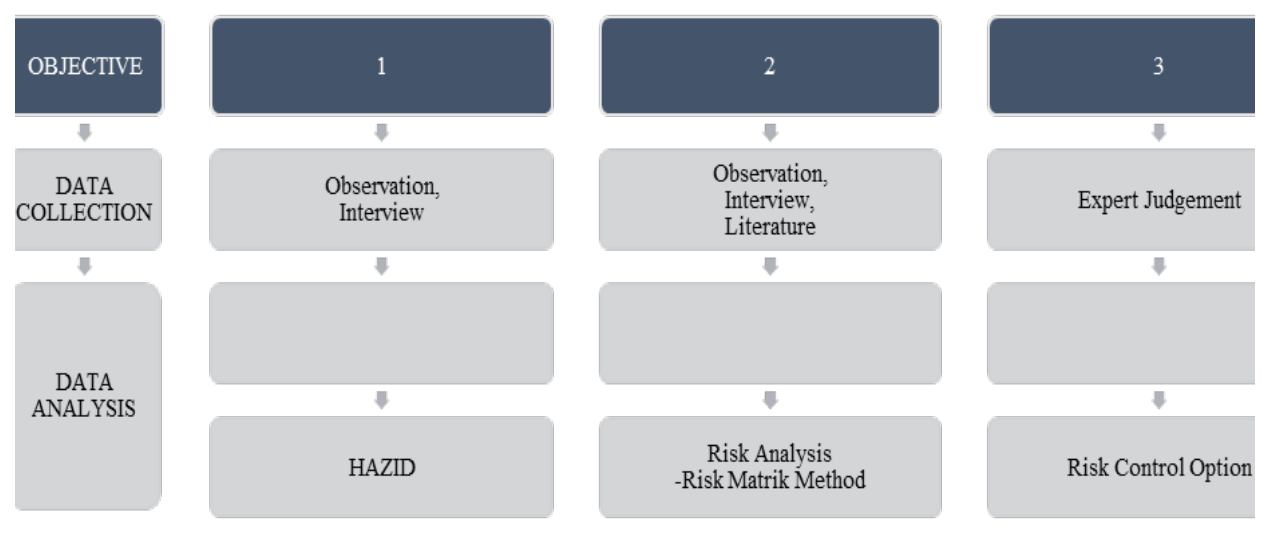

Figure 1: Research Design and Workflow

\subsection{Data Collection Process}

Collection of the data is the most important part where those data will affect the result of the research. For the research objective, the data was obtained by the observation of the current safety issues at Pulau Duyong through a site visit. Other than that, an interview was made with the water sports athletes and societies around Pulau Duyong for more comprehensive data gathering. For the first step in risk assessment, the data was obtained through Risk Matrix Analysis to obtain a better view on the level of risk and severity. For second step, the data was obtained through Risk Control Options. By this method, the best recommendations can be identified to minimize the danger. 


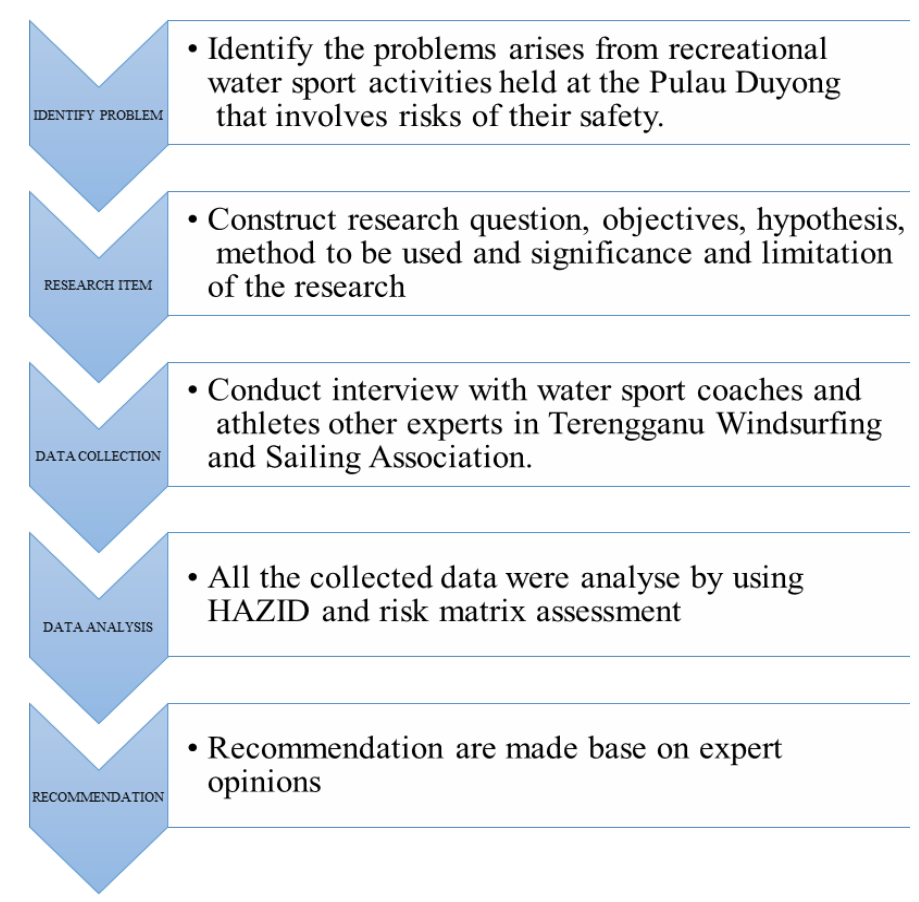

Figure 2: Research Workflow

\subsection{Data Analysis Process}

For the objective which is to identify the current safety status water sports activities at Pulau Duyong, Risk Assessment has been used as a method. A systematic method of enhancing the safety of any situation that might occur by a few processes of risk assessment steps and evaluation. Therefore, the steps in the risk assessment can be used in performing the data analysis on the risk obtained. The data analysis process involves observations on the particular area, interviews, and expert judgement. There are three steps that are applied for this research. By referring to the research design, the several steps are enhanced for better valuate of risk analysis using the risk matrix table and to record the significant findings and provide control options for each of the hazard. The steps are:

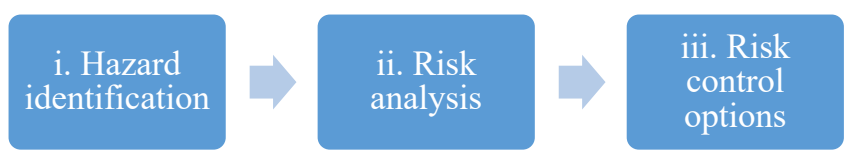

Figure 3: Risk Assessment Steps

\subsubsection{Hazard Identification}

For this research study, identification of hazards is obtained through the observation of the particular area and also interview session with the respondents of 40 people includes from the local communities, worker communities for the activities and expertise from sailing sport. This observation and interview are made to list all the hazards for the occurrence of any incidents, injuries and other related statistic.

\subsubsection{Risk Evaluation}

The second step is focused on the risk evaluation of current safety status of water sport at Pulau Duyong which is the level of the risk that occurred in the research area. This process, use risk 
matrix method. The risk matrix is a simple instrument to identify the prominence of risks and could contribute towards management decision making process. From the list of hazards that listed, the data will be transformed into an analytical table which will show the severity of each hazard to analyze the risk accordingly to severity. The risk matrix is essential to be used during risk assessment in order to differentiate the level of every risk that occur by considering the category of probability or any likelihood against the category of consequence severity. Other than that, risk can be determined as an amount of several harms that can be expected during a given time. Basically, risk matrix is being calculated as a frequency of several harm that might occur multiplied by the numbers of the severity of the harm that might occur.

High Risk: Denoted with red cells which indicates that the risk is very likely to happen and cause catastrophic event. This type of risk should be avoided immediately, strict timelines must be established to ensure that issues related to those risks are resolved before a hazardous situation becomes imminent.

Medium Risk: Denoted with orange cells which indicates that the risk is likely to happen and cause significant consequences. Reasonable steps should be taken and risk management strategies should be developed in a timely manner.

Low Risk: Denoted with green cells which indicates that the risk is low. This type of risk constitute common events and does not result in significant problems. However, some reasonable steps could assist in mitigating these type of risks. Such steps should be taken for overall improving of the situation.

\begin{tabular}{|c|c|c|c|c|c|}
\hline 2 & $\begin{array}{c}\mathbf{1} \\
\text { negligible }\end{array}$ & $\begin{array}{c}\mathbf{2} \\
\text { minor }\end{array}$ & $\begin{array}{c}\mathbf{3} \\
\text { moderate }\end{array}$ & $\begin{array}{c}\mathbf{4} \\
\text { significant }\end{array}$ & $\begin{array}{c}\mathbf{5} \\
\text { severe }\end{array}$ \\
\hline $\begin{array}{c}\mathbf{5} \\
\text { Very likely }\end{array}$ & 5 & 10 & 15 & 20 & 25 \\
\hline $\begin{array}{c}\mathbf{4} \\
\text { likely }\end{array}$ & 4 & 8 & 12 & 16 & 20 \\
\hline $\begin{array}{c}\mathbf{3} \\
\text { possible }\end{array}$ & 3 & 6 & 9 & 12 & 15 \\
\hline $\begin{array}{c}\mathbf{2} \\
\text { unlikely }\end{array}$ & 2 & 4 & 6 & 8 & 10 \\
\hline $\begin{array}{c}\mathbf{1} \\
\text { Very unlikely }\end{array}$ & 1 & 2 & 3 & 4 & 5 \\
\hline
\end{tabular}

Figure 4: Risk Matrix by Categories

\subsubsection{Risk Finding and Implementation for Risk Control Options}

This step provides the understanding on how the occurrence of each hazard can be avoided or its risks can be minimized. The most feasible risk control option will be selected. Safety risk analysis is done to determine which risk control option should be selected for practical purposes. All the risk identified are then proceed with risk control options obtained from expert's view and opinion.

\section{Result and Discussion}

In this phase, the collected data analyzed and the result from the collected data of the research be interpreted. From the data gathered, a risk matrix table can be formed to rank out the list of hazards 
identified. From the table, the risk can be ranked from least severe to most severe. Lastly, in this chapter, a few suggestions will be shown on how to improve sea sports safety at Pulau Duyong

\subsection{Hazid}

The research using observation at Pulau Duyong is one of the methods used to complete this research. Interviews were made on water sports athletes and societies with the total respondents of 40 people. A list of hazards and risks were designed after the interviews were completed. Through the list, two risk matrix table were formed consist of ten risks and range of severity depends on negligible (1-5), minor (6-10), moderate (11-15), significant (16-20) and severe (21-25). This are the listed risk which calculated by the formula of

$$
\text { Risk }=\text { Frequency } x \text { Severity }
$$

Table 1: Data on The Risk from Calculation of Frequency x Severity

\begin{tabular}{|l|c|c|c|}
\hline \multicolumn{1}{|c|}{ Risk } & Frequency & Severity & $\begin{array}{c}\text { Total (Frequency X } \\
\text { Severity) }\end{array}$ \\
\hline Drowning & 4 & 5 & 20 \\
\hline Head Hit Seabed & 4 & 4 & 16 \\
\hline Common Injuries & 4 & 4 & 16 \\
\hline Entangle in Rope & 3 & 4 & 12 \\
\hline Heat Stroke & 4 & 3 & 12 \\
\hline Cramp & 5 & 2 & 10 \\
\hline Loss of Balance & 2 & 5 & 9 \\
\hline Loss of Control & 3 & 3 & 9 \\
\hline Collision & 3 & 3 & 6 \\
\hline Drifting & 2 & 3 & \\
\hline
\end{tabular}

\subsection{Risk Evaluation}

After the HAZID process, all the data transferred to risk analysis which is done by using the risk matrix assessment. Each of the risk categorized respectively to the frequency and severity denoted by different colors as shown in table 1 .

Table 2: Catagorized Data for Each Risk

\begin{tabular}{|l|c|c|c|c|c|}
\hline \multicolumn{1}{|c|}{ RISK/SEVERITY } & $\mathbf{1}$ & $\mathbf{2}$ & $\mathbf{3}$ & $\mathbf{4}$ & $\mathbf{5}$ \\
\hline Heat stroke & $(1-5)$ & $(6-10)$ & $(11-15)$ & $(16-20)$ & $(21-25)$ \\
\hline Cramp & $(1-5)$ & $(6-10)$ & $(11-15)$ & $(16-20)$ & $(21-25)$ \\
\hline Common injuries & $(1-5)$ & $(6-10)$ & $(11-15)$ & $(16-20)$ & $(21-25)$ \\
\hline Loss of balance & $(1-5)$ & $(6-10)$ & $(11-15)$ & $(16-20)$ & $(21-25)$ \\
\hline Cause harm to athletes & $(1-5)$ & $(6-10)$ & $(11-15)$ & $(16-20)$ & $(21-25)$ \\
\hline Loss of control & $(1-5)$ & $(6-10)$ & $(11-15)$ & $(16-20)$ & $(21-25)$ \\
\hline Drowning & $(1-5)$ & $(6-10)$ & $(11-15)$ & $(16-20)$ & $(21-25)$ \\
\hline Drifting & $(1-5)$ & $(6-10)$ & $(11-15)$ & $(16-20)$ & $(21-25)$ \\
\hline Entangle in rope & $(1-5)$ & $(6-10)$ & $(11-15)$ & $(16-20)$ & $(21-25)$ \\
\hline Head hit seabed & $(1-5)$ & $(6-10)$ & $(11-15)$ & $(16-20)$ & $(21-25)$ \\
\hline
\end{tabular}




\subsection{Risk Finding and Control Option}

Table 3: Risk Control Option

\begin{tabular}{|c|c|c|}
\hline & RISK & CONTROL OPTIONS \\
\hline 1 & Heat stroke & $\begin{array}{l}\text { - Increase intake of water before and after activities; } \\
\text { - Don permeable clothing with sun protective } \\
\text { qualities; }\end{array}$ \\
\hline 2 & Cramp & $\begin{array}{l}\text { Practice warming up before sports activity to } \\
\text { maintain elasticity of muscle and flexibility; } \\
\text { - Adequate rest period prior to taking part in sea sport } \\
\text { activities; }\end{array}$ \\
\hline 3 & Out of shape / Fatigue & $\begin{array}{l}\text { Acquire appropriate training on the right techniques } \\
\text { and skills; }\end{array}$ \\
\hline 4 & Bad weather condition & $\begin{array}{l}\text { - Recognize all signals, including public } \\
\text { announcements and flag signals; } \\
\text { - Immediately stop all activities when insight with } \\
\text { lightning in the nearby area }\end{array}$ \\
\hline 5 & Improper facilities & - Proper maintenance should be done \\
\hline 6 & Equipment failure & $\begin{array}{l}\text { - Frequently check any equipment before and after of } \\
\text { the activities }\end{array}$ \\
\hline 7 & Drowning & $\begin{array}{l}\text { - Shall have basic skill such as swimming for survival } \\
\text { - Wear the right buoyancy aids at all-time especially } \\
\text { on the water }\end{array}$ \\
\hline 8 & Drifting & $\begin{array}{l}\text { - Have appropriate supervision nearby during the } \\
\text { water activity }\end{array}$ \\
\hline 9 & Entangle in rope & $\begin{array}{l}\text { Ensure proper setup of equipment such as rigging for } \\
\text { sailboats }\end{array}$ \\
\hline 10 & Capsize & $\begin{array}{l}\text { - Learn the right technique to avoid capsizing in any } \\
\text { condition }\end{array}$ \\
\hline
\end{tabular}

\section{Discussion and Recommendation}

\subsection{Recommendation}

From this research, proper analysis of data was made to highlights the important result. The results are shown in the following pie charts to illustrate the risks of accidents from sea sports that are classified into 4 major classes of risks that are: general risks, weather, water and equipment (kit). 
Figure 4, shows the general risk which states the highest level of risk at $39 \%$ from the common injuries. These injuries include cuts and bruises which are normally do happen in all kinds of sea sport all the time. A few ways to reduce this risk is to have more practice to familiarize on the sport. Thus, this shall reduce the percentage of this risk to occur. In the contacts of risk in weather, the risk of heat stroke and exhaustion top on the highest percentage of risk in weather class. Both stating $31 \%$. The best recommendation to reduce these risks is to always check on weather condition before sea sports activity or training. Always drink a lot of water to reduce dehydration with will cause exhaustion. The equipment class states the highest percentage of risk is entangled in ropes at $72 \%$. These common problems are due to improper setup of equipment such as rigging for sailboats. Recommendation for reducing the percentage of this risk is to check the equipment before going into the sea. Also, always check the condition of the equipment to be always at good condition.
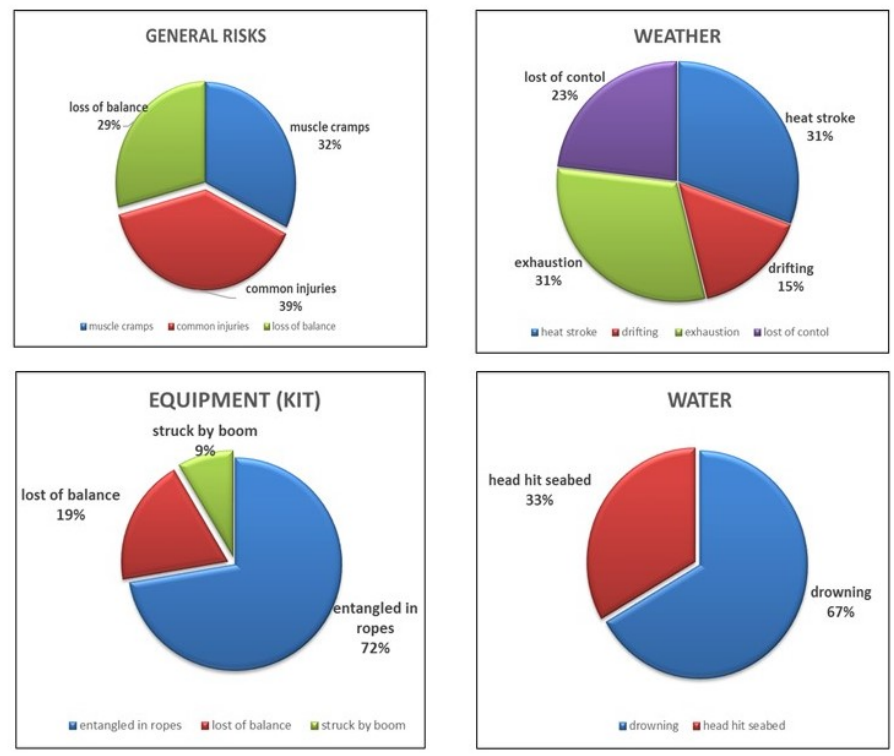

Figure 5: Major Classes of Risks

Figure 4 shows, about $67 \%$ of risk in water class is drowning. This arises due to lack of basic swimming skills and panic attack that increases the chances of drowning. Best way to reduce the risk of drowning is to always wear a floatation aid at all time when in water. It is also suggestible that knowledge of swimming becomes a priority in everybody.

\subsection{Conclusion}

All of the results and information which were obtained through observation and interviews are gathered in the discussion. The objectives were accomplished through the risk assessment steps with the identification of hazard and evaluation of hazard as listed in the result which indicates the severity level for each of the hazard. Moreover, with the expert's views on this research helps in accomplishing the risk matrix and risk control options which provides possible recommendation and solution on safety issues in sea sports. Based on our findings, there were many hazards that contributes to the water sport accidents in Pulau Duyong. Most accident involving sea sport activities are equipment, general risk, weather and water which shown by its respective percentages. From all of the control option that was identified were able to provide the solution of unwanted incident to improve the safety of sea sport in Pulau Duyong. 
In this research, some future improvement can be recommended to improve the safety status in Pulau Duyong. Firstly, time is the most important factor in conducting this research, future research shall be done in longer time frame to have more comprehensive result in identifying the hazard and analyzing the data. From the all collected data, it can be said that, the area which recreational activities take place can be literally identified. Next, maybe the organization that has responsibilities should observe the level of safety of sea sport so that higher safety level can be implemented. Even though the average number of accident at Pulau Duyong is low among athletes and recreational sea sport participant, precaution should be taken by organizations to plan and monitor their area of responsibility so that the safety of sea sports is always preserved.

\section{Acknowledgment}

The authors expressed their gratitude to the coaches and athletes from Terengganu Windsurfing and Sailing Association (TWSA) for their expert contribution, the Terengganu State Sport Council (MSNT) for consent on use of sea sports data in Pulau Duyong. Finally, they would also like to extend their deepest gratitude to all those who have directly or indirectly guided them in this study.

\section{References}

[1]The Importance of Safety Equipment in Sports and Exercise. (2010). Retrieved from Motley Health: http://www.motleyhealth.com/fitness/the-importance-of-safety-equipment-in-sports-and-exercise

[2] Warren, J. (2017, January 12). Safety Guidelines for Outdoor Water Sports. Retrieved from There is a vast diversity in the types of water sports activities. Some of the more popular include: swimming, scuba diving, fishing, boating, sailing, tubing, surfing and wakeboarding: http://www.n-georgia.com/water-safety2.html

[3] Dermawan, A. (2017, October 11). New Straits Times. Retrieved from 700 drowning cases recorded in Malaysia every year: https://www.nst.com.my/news/nation/2017/10/289879/700-drowning-cases-recorded-malaysia-everyyear

[4] Jong, J. B. (2006, February 9). National Center for Biotechnology Information, U.S. National Library of Medicine. Retrieved from Sailing and sports medicine: a literature review: https://www.ncbi.nlm.nih.gov/pmc/articles/PMC2653898/

[5] Leisure and Cultural Services Department. (2014). Potential Hazards during Water Sports Activities. Retrieved from The Government of Hong Kong Special Administrative Region: http://www.lcsd.gov.hk/en/watersport/guideline/guid_hazards.html

[6] Quinn, E. (2011, September 11). Essential Safety Equipment for Sports. Retrieved from Prevent sports injuries with basic sports safety equipment: https://www.verywell.com/essential-safety-equipment-for-sports-3120458

[7] TWSA (2017). Water Sport In Terengganu. (I. Hasbullah, Interviewer)

[8] Burgon, R. (2013, January 21). The Five Step Guide to Risk Assessment. RoSPA Workplace Safety Blog. Retrieved 29 March 2018. https://rospaworkplacesafety.com/2013/01/21/what-is-a-risk-assessment/

[9] Executive, H. A. (2013). Controlling the risks in the workplace. Retrieved from Health and Safety Executive: http://www.hse.gov.uk/risk/controlling-risks.htm 